\title{
Deslocamentos do imperativo visual em recortes do feminino
}

\author{
Dislocations of visual imperative in women segments \\ Luciana Abreu Jardim* \\ Universidade Federal do Rio Grande, Rio Grande, Rio Grande do Sul, Brasil
}

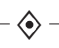

Resumo: Possíveis aproximações entre Ética e Literatura deveriam ser pensadas a partir dos desdobramentos propostos pelo questionamento da metafisica da presença, de Da gramatologia, ponto central do pensamento derridiano. Para escrever para além da metafísica da presença, abalada por Jacques Derrida, deve-se sair da saturação de visibilidade contemporânea, de modo a buscar novas experiências com a linguagem. A modalidade linguística do semiótico, por exemplo, de acordo com o modelo linguístico de Julia Kristeva (A revolução da linguagem poética), propõe uma experiência na qual aspectos da vida escrita sejam capazes de produzir sentidos sutis, sempre em copresença com a modalidade do simbólico. Nesse contexto teórico, alguns fragmentos textuais de Clarice Lispector, os quais podem ser lidos ao lado do elenco de pensadoras do gênio feminino segundo Kristeva, pavimentam o caminho para algo diferente da timpanização flagrada por Derrida. Assim, este ensaio apresenta uma leitura dos caminhos oblíquos que conduzem às tensões entre a sensação e o pensamento, no cruzamento entre Ética e Estética, sugerindo alguns recortes textuais característicos da singularidade da escrita produzida por mulheres.

Palavras-chave: Ética; Literatura; Escrita feminina

\begin{abstract}
The possible relationship between ethics and literature should be thought from the outcome the questioning of metaphysics of presence proposes; from De la Grammatologie (DERRIDA, 1967), the framework of Derridas's thought. In order to write beyond metaphysics of presence, unsettled by Derrida, it is necessary to move away from extreme contemporary visual stimulation to search for new language experiences. The linguistic mode of the semiotics, for instance, according to Julia Kristeva's linguistic model (Revolution in Poetic Language, 1974), suggests that an experience in which aspects of the written life be able to produce subtle meanings, always co-present with the symbolic mode. In this theoretical context, some extracts of texts by Clarice Lispector, which can be read side by side with women genius thinkers, according to Kristeva, pave the way to something different from the tympanites caught by Derrida. As a result, this essay shows an interpretation of the slantways that lead to the tensions between feeling and thinking when it comes to the crossing of Ethics and Aesthetics, which suggests reflection on some typical textual segments of the written singularity produced by women.
\end{abstract}

Keywords: Ethics; Literature; Women's writing

Can I help you?

(Yohji Yamamoto - Notebook on cities and clothes)

* Pós-doutoranda em Letras FURG,PNPD/Capes. 


\section{A existência e o texto}

Ao escrever sobre Antonin Artaud, no ensaio intitulado "A palavra soprada", Jacques Derrida, em discreta nota de final de página, oferece interessante caminho interpretativo para a leitura da noção de diferença. $O$ peso dessa escolha derridiana está no fato de que, na produção de Artaud, um texto, fragmento de carta ou até mesmo algum autorretrato inexpressivo, conduzem ao conjunto de sua obra. Os críticos do dramaturgo não escapam de uma leitura em que vida e obra formam um único tecido de posse e conflito ${ }^{1}$. E quando Derrida recusa o que chama de "referência biográfica" é simplesmente para consolidar o seu projeto desconstrutivista de rejeição a oposições duais em virtude de interpretações totalizantes. Ao retomar um fragmento de texto de Artaud no qual está escrito "Caro amigo, o que tomastes como obras minhas era apenas o que não se aproveitava de mim próprio" (Le Pèse-Nerfs, I, p. 95), Derrida, sem apagar a relação de embaralhamento entre o dentro e o fora, apenas realça a necessidade do não-idêntico, que é um dos sentidos do verbo diferir. Na sequência de recortes de textos de Artaud que trazem à tona conteúdo excremencial, Derrida procura por um "novo estatuto" para a relação entre "existência e texto":

Abstivemos deliberadamente, como é natural, de tudo o que se denomina "referência biográfica". Se recordamos neste momento preciso que Artaud morreu de um câncer no reto, não é para que a exceção feita confirme a regra boa, mas porque pensamos que o estatuto (ainda por encontrar) desta observação e de outras semelhantes, não deve ser o da "referência biográfica". O novo estatuto - ainda por encontrar - é o das relações entre a existência e o texto, entre essas duas formas de textualidade e a escritura geral no jogo da qual se articulam] (DERRIDA, 2002, p. 127, grifos nossos).

Em Da gramatologia, na tentativa de abalar a primazia da fala, a técnica da escrita perde o caráter negativo, exterior à linguagem, na medida em que o par dentro/fora é desconstruído por Derrida. Como uma temática secundária, a questão confessional dos textos de Rousseau retoma o que já havia sido alinhavado por Derrida ao chamar à cena filosófica a produção de Artaud. O filósofo recusa o vínculo entre confissão e verdade que geralmente se estabelece quando o próprio autor, em gestos confessionais, ou seus biógrafos, em recortes muitas vezes carregados de um conteúdo fantasmal

\footnotetext{
1 Os importantes trabalhos de Paule Thévenin (1993) e de Florence de Mèredieu (2006) constituem exemplos da relação entre vida e obra em análises artaudianas.
}

distante do próprio protagonista da história, parecem tocar em zonas inquestionáveis de apreensão da experiência vivida. Veremos que na citação a seguir Derrida, ao evocar a diferença, reforça a impossibilidade da narração de uma vida em sua plenitude e também aproxima a diferença do conceito de suplemento:

Tampouco se deve buscar uma verdade significada por esses escritos (verdade metafísica ou verdade psicológica: a vida de Jean-Jacques atrás de sua obra) pois, se os textos por que vamos interessar-nos querem dizer alguma coisa, é o engajamento e a pertecença que encerram no mesmo tecido, no mesmo texto, a existência e a escritura. $\mathrm{O}$ mesmo aqui se denomina suplemento, outro nome da diferencia (DERRIDA, 1999, p. 183-184, grifos nossos).

Nessa medida, em Da gramatologia, Derrida nos convida a vasculhar nos próprios textos dos autores índices para possíveis interpretações, o que é mais sofisticado do que apenas entrar em contato com a aparente profundidade dos autores através de suas confissões ou sustentar teses a partir de histórias e dados coletados por biógrafos. "Não existe, a rigor, texto cujo autor ou sujeito seja Jean-Jacques Rousseau", sustenta Derrida (2002, p. 300). Podemos afirmar que por não haver um fora do texto, a vida já está no próprio texto ${ }^{2}$. Suspeitamos que o novo estatuto da referência biográfica participa do sentimento de pertencimento que foi esboçado na última citação. Curiosamente, o tema do pertencimento retorna em entrevista concedida à psicanalista Elisabeth Roudinesco. Sobre a experiência no liceu Maimônides, o autor comenta: "Acho que foi lá que comecei a reconhecer, se não a contrair essa doença, esse mal-estar, esse malestar que, durante toda a minha vida, me tornou inapto à experiência "comunitária", incapaz de desfrutar de um pertencimento qualquer" (DERRIDA, 2004, p. 135).

Nietzsche está possivelmente na origem dessa questão sobre a relação entre "existência e texto", sobretudo no momento em que promove um afastamento entre a sua escrita e a percepção de si mesmo, distanciando-se assim do que é aparentemente idêntico: "Uma coisa sou eu, outra são meus escritos" (Ecce Homo, Por que escrevo tão bons livros, 1995, §1, p. 52). Assim como se desvela em Derrida, há nas confissões nietzschianas um estado de mal-estar, de acordo com a afirmação: "Foi a doença que me trouxe à razão" (Ecce Homo, "Por que sou tão sábio, 1995, p. 40). "O médico diz: paralisia facial de origem "periférica", eletromiograma e scanner, o espectro cruel desse olho esquerdo que não pisca mais, vejo-o dissimetrizar minhas figuras, olha-me a partir de minha

\footnotetext{
2 A sugestão de ligação entre vida e obra está presente no ensaio "Derrida e a razão diferencial", de Ricardo Timm de Souza.
} 
mãe chispas nos olhos, como para anestesiar a visão do horror, pois sem fraquejar preciso descrever a escara de minha vida, [...]" (DERRIDA, 1996, p. 79). "A doença deu-me igualmente o direito a uma completa inversão de meus hábitos; ela permitiu, ela me ordenou esquecer; ela me presenteou com a obrigação à quietude, ao ócio, ao esperar a ser paciente... Mas isto significa pensar!" (Ecce Homo, "Humano, demasiado humano com duas continuações, 1995 §4, p. 72). Em A gaia ciência, o tema da doença retorna sob a sugestão de se pensar sobre o conceito de vida, ao lado de outros que tocam o tema do corpo, sendo, portanto, um desafio para os filósofos do futuro:

[...] frequentemente me perguntei se até hoje a filosofia, de modo geral, não teria sido apenas uma interpretação do corpo e uma má-compreensão do corpo. [...] Eu espero ainda que um médico filosófico, no sentido excepcional do termo - alguém que persiga o problema da saúde geral de um povo, uma época, de uma raça, da humanidade -, tenha futuramente a coragem de levar ao cúmulo a minha suspeita de arriscar a seguinte afirmação: em todo o filosofar, até o momento, a questão não foi absolutamente a "verdade", mas algo diferente, como saúde, futuro, poder, crescimento, vida... (NIETZSCHE, 2007, §2, p. 12, grifos nossos).

Derrida, ao desconstruir a primazia da fala em $D a$ gramatologia, encarregou-se de pensar sobre o conceito de vida em relação à técnica, incluindo na sua escolha também reflexões a respeito do futuro. O estatuto entre "existência e texto", que foi apontado em Da gramatologia através do abalo entre as posições bem marcadas entre o dentro e o fora, pode ser encontrado em Circonfissão ou em $O$ cartão-postal, para citar alguns exemplos. O conceito de vida acompanha o projeto de desconstrução - essa é uma observação importante. Se os binarismos foram abalados, a vida deixa de existir em oposição à morte. E a morte perde a sua função trágica de apontar para a nossa finitude e/ou para a irreversibilidade contida nessa experiência final. Nessa perspectiva, algo de morto também participa da vida ${ }^{3}$.

\begin{abstract}
Meu pai morreu com trinta e seis anos: ele era suave, amável e mórbido, como um ser destinado a simplesmente passar - antes uma bondosa lembrança da vida do que a vida mesma. No mesmo ano em que sua vida cedia, também a minha declinava: aos trinta e seis anos atingi o ponto mais baixo de minha vitalidade - ainda vivia, sem no entanto enxergar três passos adiante (NIETZSCHE, 1995, p. 23)
\end{abstract}

\footnotetext{
3 "Un discours sur la vie-la-mort doit occuper un certain espace entre logos et le gramme, l'analogie et le programme, les différents sens du programme et de la reproduction. Et puisqu'il y va de la vie, le trait qui rapporte logique à graphique doit bien travailler aussi entre la biologie et le biographique, le thanatologique et le thanatographique" Derrida. Otobiographies. L'enseignement de Nietzsche et la politique du nom propre. Paris: Galilée, s/d, p. 39.
}

Não é apenas o fantasma de papai que participa da vida-morte, há a confissão de decadência física que leva o filósofo à escuta, desconstruindo possivelmente a primazia do olhar que compõe a história da filosofia. Nesse sentido, sustentamos que a desconstrução da metafísica da presença proposta por Derrida depende da valorização desse deslocamento circular entre metáforas nietzschianas do olho e do ouvido. O gesto de "Timpanizar" a filosofia é defendido por Derrida como conquista da atividade de fazer filosofia em margens, dobras, movimentos disseminadores de sentidos escorregadios, formações delicadas, assim o autor reproduz a interrogação de Zaratustra sobre a possibilidade de perfurar os ouvidos dos aprendizes com instrumentos de percussão ${ }^{4}$. Zaratustra, segundo Derrida, desempenha o papel de chamar a atenção para o "ouvir com os olhos" (DERRIDA, 1991, p. 13). Todavia, esse gesto dependente do corpo só se torna possível quando a relação binária entre o pensar/sentir se desestrutura para dar espaço a zonas de contaminação entre os termos, o que não significa uma simples inversão para promover a esfera dos afetos. ${ }^{5}$

\section{O pensar o e o sentir}

Com o objetivo de desfazer a condição negativa atribuída à escrita em Da gramatologia, Derrida retoma o modelo de Saussure exposto no Curso de linguística geral. A posição de Saussure em O curso de linguística geral é a de manter a hierarquia entre a fala e a escrita, que leva ao rebaixamento da relevância da escrita na constituição do signo. Derrida recorta do VI capítulo desse curso a seguinte afirmação: “"A língua independe da escritura" (Saussure apud Derrida, 1999, p. 50). Desse modo, a diferença entre significante e significado privilegia um dos lados: o da voz. A voz corresponde ao dentro, ao necessário, ao natural à humanidade e ao campo dos afetos (o interior). Cabe à escrita o lado de fora do signo, o exterior, o artificial, o suplemento; por isso Derrida alude a um "perigoso suplemento", que desenha a questão da técnica por um viés limitado. Em Da gramatologia, Derrida argumenta que o modelo de Saussure apenas acompanha a oposição entre o sensível e o inteligível, sendo, portanto, ingenuamente derivado da história da filosofia. O retorno do filósofo ao esboço da ideia de signo em textos de Platão e de Aristóteles,

\footnotetext{
4 Cf. "Timpanizar a filosofia”. In: Margens da filosofia, p. 11-31.

5 Aqui está uma timpanização cujo efeito recai sobre o tema a "existência e texto": "Gradualmente foi se revelando para mim o que toda grande filosofia foi até o momento: a confissão pessoal de seu autor, uma espécie de memórias involuntárias e inadvertidas; e também se tornou claro que as intenções morais (ou imorais) de toda filosofia constituíram sempre o germe a partir do qual cresceu a planta inteira. De fato, para explicar como surgiram as mais remotas afirmações metafísicas de um filósofo é bom (e sábio) se perguntar antes de tudo: a que moral isto (ele) quer chegar?" (NIETZSCHE, 1992, §6, p. 13).
} 
seguindo Da gramatologia, serve para realçar a distinção antitética entre o pensar e o sentir.

A teoria da linguagem que o autor observa em Émile, de Rousseau, acompanha a distinção histórica entre o prélinguístico (grito, animal) e o linguístico (fala, homem), sendo o período da infância ou a ideia de Deus o momento de desenvolvimento de uma voz que Derrida questiona como sendo a "voz natural" (DERRIDA, 1999, p. 300). Derrida seleciona um trecho dessa teoria para evidenciar a recusa que é atribuída à escrita. No exemplo a seguir, o modelo linguístico de Rousseau reproduz um projeto que, para Derrida, também participa da separação entre o sensível e o inteligível articulado por Platão e Aristóteles, na medida em que sustenta a posição de "uma língua pura de toda a suplementaridade":

Todas as nossas línguas são obras da arte. Pesquisouse por muito tempo se haveria uma língua natural e comum a todos os homens; sem dúvida, ela existe e é a que as crianças falam antes de saberem falar. Esta língua não é articulada, mas é acentuada, sonora, inteligível. [...] E, embora pronunciem palavras, tais palavras são perfeitamente inúteis: não é o sentido das palavras que os nenês entendem, mas o acento que o acompanha (ROUSSEAU apud DERRIDA, 1999, p. 301).

Todavia, o passo de Rousseau não fica estagnado numa simples separação entre o pensar e o sentir, uma vez que o espaço que ele oferece à figura materna, que não é evidenciado por Derrida nessa reconstrução de uma possível teoria da linguagem desse pensador, não é percebida aqui por Derrida como uma estratégia interessante que abala o binarismo pensar/sentir. Ora, Derrida, em Da gramatologia, não enfatiza o fato de que não existem sujeitos falantes sem mamães. Ao reconhecer que Rousseau explicava sua teoria da linguagem por meio de "estrutura da paixão e da afetividade" (DERRIDA, 1999, p. 335), Derrida deveria pôr em cena a mediadora desse processo, aquela que viabiliza as paixões do bebê (futuro sujeito falante) e as modela numa teia de afetos para a vida em sociedade.

Em A revolução da linguagem poética (1974), Julia Kristeva, sem mencionar o pensamento de Rousseau e, no entanto, muito próxima de seus escritos sobre a linguagem, ao mesmo tempo afastando-se de teorias da linguagem influenciadas pelo cogito cartesiano ou pela fenomenologia husserliana, voltará ao tema de teor desconstrutivista referente ao pensar/sentir. As modalidades linguísticas do semiótico e do simbólico, que a seguir explicaremos, embasam a teoria linguística de Kristeva. Da mesma forma que Derrida recorre ao Timeu para retomar o tema do falocentrismo característico da composição da filosofia (em Khôra), Kristeva também buscará no texto platônico embasamento para a construção de sua chora semiótica. A chora, segundo a interpretação da autora, desempenha o papel de uma articulação incerta e indeterminada, não levando a uma disposição ou a uma representação, características que, segundo a autora, a aproximariam da intuição fenomenológica espacial e, por conseguinte, de uma geometria. A chora caracteriza-se por uma "articulação provisória", "essencialmente móvel", constituída de movimentos e de estases efêmeros" (KRISTEVA, 1974, p.23). Em função desses constantes movimentos, a chora aproxima-se de um ritmo, sendo anterior à espacialidade e à temporalidade. A chora não serve como posição para algo ou alguém. A chora admite - na verdade ela apenas tolera - analogias com o ritmo vocal ou cinético. Kristeva também expõe, com base no texto platônico, um aspecto feminino e maternal da chora: "ele designa esse receptáculo como nutritivo e materno" (KRISTEVA, 1974, p. 25). Não apenas maternal e acolhedora, a chora também se caracteriza pelo fato de não constituir unidade, logo fica privada da ideia de Deus, da ideia de identidade. Cabe a ela, entretanto, a capacidade de manter constante renovação, dado que articula provisoriamente quantidades discretas de energia. Tal movimento percorre o corpo daquele que será, passado esse processo dos primeiros meses de vida, um sujeito falante. A chora semiótica está na origem do semiótico. Essa modalidade linguística, que não se reduz à linguagem propriamente dita, mas atua de modo a cortá-la transversalmente, é formada por vetores sensoriais tais como o som (melodia e ritmo), a cor, o odor e os gestos, sendo relacionada ao corpo materno. Kristeva explica que o semiótico se liga à teoria do sujeito no plano do inconsciente; além disso é anterior à significação, atuando no que chama de pré-tético. Essa função é por ela assim definida: "Isso que chamamos de uma função tética não é outra coisa senão a posição da enunciação de um sujeito falante através de um sintagma ou uma proposição: as distinções nome/verbo etc. são posteriores a esta função [...]." (KRISTEVA, 1974, p. 54). Dado que o semiótico é anterior à significação, Kristeva resume esse funcionamento na ordem do que antecede à instauração do simbólico (KRISTEVA, 1974, p. 35). Em As novas doenças da alma, Kristeva atribui à modalidade do semiótico um sentido pulsional e afetivo. Nesse sentido, a questão dos afetos abre caminho para a possível originalidade da teoria linguística de Kristeva, que é, desde $A$ revolução da linguagem poética (1974), amplamente baseada no legado psicanalítico de Freud 6 . Para Kristeva, o assunto

\footnotetext{
6 André Green, em Le discours vivant, ao percorrer os caminhos do afeto na teoria psicanalítica de Freud, chama a atenção para a dificuldade dessa tarefa. Conforme Green, o próprio Freud promove o apagamento das nuances sobre esse tema ao misturar termos alemães como Empfindung (sensação) e Gefühl (sentimento) por afeto, o qual, na língua alemã tem um correspondente específico: Affekt.
} 
dos afetos ainda é pouco explorado tanto no conjunto freudiano quanto em sua própria teoria; no entanto parece ser o centro da formação do semiótico e o atributo que leva à desconstrução do pensar/sentir. O simbólico, a outra modalidade da linguagem, se manifesta por meio de signos linguísticos e de determinada ordenação sintática. A ruptura da hierarquia entre o pensar/sentir reside na codependência dessas modalidades. $\mathrm{O}$ fato de o semiótico ser o primeiro não significa a sua superioridade sobre o nível simbólico, dado que o semiótico só atua - e sua atuação é transversal - através de regras sociais dispostas gramaticalmente pelo nível simbólico. Além disso, é preciso voltar ao conceito de significância (signifiance), que é um terceiro elemento, que se soma ao par codependente, viabilizando essa interação. A investigação dos afetos envolvidos durante esse processo contribuiria para a explicação do cruzamento das diversas áreas pelas quais Kristeva transita, levando-a a um constante questionamento sobre o assunto.

Poetas de vanguarda como Ducasse (Lautréamont) e Mallarmé, que foram estudados por Kristeva em A revolução da linguagem poética, transgrediram e inovaram a linguagem porque trabalharam os elementos semiotizáveis no interior de regras de uma sintaxe movida por códigos estabelecidos pela cultura. Eles interferiram num plano fônico-acústico-pulsional que repercutiu sobre o social e seus textos ainda causam estranhamento em leitores da atualidade, porque tais inovações linguísticas estão entrançadas em experiências (existências) que na teoria de Kristeva se condensa sob a sugestão afetiva (sons, ritmos, cores, odores) - o que é diferente de estrutura, estando, assim, próximo da sugestão do conceito de vida, que está em Nietzsche e reaparece em Derrida.

A respeito do conceito de vida, nota-se que no prólogo de $A$ gaia ciência, pensar e sentir inauguram a sugestão de copresença entre os termos aparentemente antitéticos: "Ele parece escrito na linguagem do vento que dissolve a neve: nele há petulância, inquietude, contradição, atmosfera de abril" (NIETZSCHE, 2007, $\S 1$, p.9). Nota-se um interessante estado de derretimento embutido na imagem da neve que dissolve a separação marcada pelo pensar/sentir, levando ao campo do "pensamento" tonalidades afetivas. E o vento é uma das origens da proposta derridiana de disseminações.

Em Genealogia da moral, observamos o retorno do mesmo pensamento: "Mas eliminar a vontade inteiramente, suspender os afetos todos sem exceção, supondo que o conseguíssemos: como? - não seria castrar o intelecto?..." (Terceira dissertação - o que significam os ideais ascéticos? 1998, §12, p. 109). Em Além do bem $e$ do mal, a questão dos afetos na linguagem se torna mais complexa do que a evidência da copresença entre e o pensar e o sentir. Observa-se que a interpretação nietzschiana do conceito de vontade de Schopenhauer investiga o "querer" como algo para além desse pensar e sentir copresentes sobre o qual nos detivemos. Sem desfazer essa copresença importante ${ }^{7}$, Nietzsche oferece um terceiro elemento ao par, que é absorvido e/ou envolvido de modo a ser comandado por tal elemento: o afeto. Segundo o autor: "a vontade não é apenas um complexo de sentir e pensar, mas sobretudo um afeto: aquele afeto do comando. O que é chamado "livre arbítrio" é, essencialmente, o afeto de superioridade em relação àquele que tem que obedecer" (NIETZSCHE, $\S 19$, p.23). O estático na teoria nietzschiana, através da exposição da impossibilidade do livre arbítrio, precisa ser reinterpretado ao lado do conceito de eterno retorno e da recorrência de imagens gélidas, as quais levam o filósofo a petrificações deslizantes. Gestos que poderiam afastá-lo da figura materna na confecção de uma teoria da linguagem, mas que, curiosamente, em Humano, demasiado humano, o aproximam das modalidades do semiótico e do simbólico:

$\mathrm{O}$ intelecto feminino - $\mathrm{O}$ intelecto das mulheres se manifesta como perfeito domínio, presença de espírito, aproveitamento de toda vantagem. Elas o transmitem aos filhos, como sua característica fundamental, e a isso o pai acrescenta o fundo mais obscuro da vontade. A influência dele determina, por assim dizer, o ritmo e a harmonia com que a nova vida deve ser tocada; mas a melodia vem da mulher (NIETZSCHE, 2000, $\S 411$, p. 225).

\section{Recortes para possíveis Palato(bio)grafias}

O palato forma o teto curvo da boca e o assoalho das cavidades nasais. Separa a cavidade oral das cavidades nasais e da parte nasal da faringe, a parte da faringe superior ao palato mole. A parte superior (nasal) do palato é coberta de mucosa respiratória, e a face inferior (oral) é coberta por mucosa oral, densamente povoada por glândulas. O palato possui duas regiões: o palato duro anteriormente e o palato mole posteriormente.

(Moore, Keith L. Anatomia orientada para a clínica)

Voltemos a uma nota discreta de $A$ revolução da linguagem poética na qual Kristeva enfatiza o lado

\footnotetext{
Existem camadas que compõem o querer (equivalente ao sentir) e o pensar: "digamos que em todo querer existe, primeiro, uma pluralidade de sensações, a saber, a sensação do estado que se deixa, a sensação do estado para o qual se vai, a sensação desse "deixar" e "ir" mesmo, e ainda uma sensação muscular concomitante, que, mesmo sem movimentarmos "braços e pernas", entra em jogo por uma espécie de hábito, tão logo "queremos". Portanto, assim como sentir, aliás muitos tipos de sentir deve ser tido como ingrediente do querer, do mesmo modo, e em segundo lugar, também o pensar: em todo o ato da vontade há um pensamento que comanda; -- e não se creia que é possível separar tal pensamento do "querer", como se então ainda restasse vontade!" (Nietzsche. Além do bem e do mal, 1992, §19, p. 23).
} 
protetor do feminino: "O espaço-receptáculo platônico é uma mãe e um alimento" (KRISTEVA, 1974, p.25). Do feminino não se espera a morte; e, sabemos, dar à luz ainda é função feminina. Pode-se esperar uma vidaà-morte inspirada na circularidade que o conceito do eterno retorno induz na imaginação. A vida-à-morte sob uma perspectiva do feminino, no entanto, ao lado da desconstrução do par dentro/fora, participa de um jogo diferente do proposto por Derrida, mais próximo talvez de movimentos textuais de Hélène Cixous. O tema da morte foi escolhido pela escritora para um ciclo de palestras em língua que não é a francesa. Tão estrangeira quanto Derrida e sendo a escritora amiga dele, percebemos que a palestra de abertura de Cixous é também homenagem a um homem desconstruído. A primeira fala intitulou-se "We need a Dead (wo)man to Begin"8. Na primeira referência literária, encontramos o nome da escritora Clarice Lispector. Como ler a morte em textos claricianos é exercício solitário, abandonamos a interpretação de Cixous para expor brevemente a nossa leitura9.

Subjaz à descrição das mortes claricianas a ideia de perecibilidade e seu estreito vínculo com a morte antecipada por uma construção técnica. O perecível a ser investigado é tema de Lispector em vários escritos, atravessando tanto assuntos filosóficos relacionados ou não ao gênero quanto temáticas da própria teoria da literatura. Em Água viva, a força protagonal, acompanhando a diferença derridiana, fracassa na tentativa de abarcar o instante-já de seu relato "bio" (equivalente filosófico-literário da filosofia de

\footnotetext{
8 H. Cixous. Three steps on the ladder of writing. New York: Columbia University Press, 1993.

9 Em Perto do coração selvagem, romance de estreia de Clarice Lispector, a protagonista de nome Joana brinca com a boneca Arlete, que é, nas fabulações infantis da personagem, abruptamente interrompida por um carro. - "Um carro azul atravessava o corpo de Arlete, matava-a". Estranho retorno do nome Arlete em personagem cuja função é a de desencadear a morte da protagonista Virgínia, em o romance O lustre: "atravessou pálida a rua e o carro dobrou a esquina, ela recuou um passo, o carro hesitou, ela avançou e o carro veio em luz, ela o percebeu com um choque de calor sobre o corpo e uma queda sem dor enquanto o coração olhava aceso para nenhum lugar" (1999, p. 258). Enquanto Virgínia vive intensamente a interrupção final, os transeuntes, sem qualquer tato, reúnem-se ao redor do corpo, personagem anônima para eles, para assistir ao gozo final (Sade): - Esses chauffeurs são malucos, meu filho um dia ia sendo atropelado mas felizmente... (1999, p. 260). Desenha-se na personagem atropelada o fracasso de uma vida sem laços afetivos que a reduz, tristemente, mesmo na morte pública, primeiro a seus objetos pessoais e somente depois aos estilhaços de uma existência em apagamento: "[...] ele a viu no chão com os lábios brancos e tranqüilos, o rolo dos cabelos desfeito, o chapéu de palha marrom amassado. Então era mesmo ela" (1999, p.262, grifos nossos). Há também a morte de Macabéa. “Algumas pessoas brotaram no beco não se sabe de onde e haviam se agrupado em torno de Macabéa sem nada fazer assim como antes pessoas nada haviam feito por ela, só que agora pelo menos a espiavam, o que lhe dava uma existência" (1999, p.81). Diversamente do narrador de $O$ lustre, em que a hora da estrela de Virgínia é interrompida ou desrespeitada por sussurros e tolices, em $A$ hora da estrela, o silêncio é incomum. É como se todos acompanhassem esse último desejo voraz de pensar-sentir de Macabéa, nunca percebido pelo seu criador Rodrigo S.M., mas que se manifesta na descrição desse narrador desatento: "Ficou inerme no canto da rua, talvez descansando das emoções, e viu entre as pedras do esgoto o ralo capim de um verde da mais tenra esperança humana" (1999, p. 80).
}

Nietzsche na formulação do conceito de vida e também do estatuto por vir entre a "existência e o texto" para Derrida) em experiência "perecível". Em Possessões, romance policial metafísico, Kristeva escreve sobre a condição perecível:

A lâmina comprime a carne rígida do pescoço. A pele do pescoço é a primeira que envelhece, numa mulher; todas as manhãs Pauline belisca essa maçã cozida, se aborrece mais ou menos ternamente ao vê-la escurecer, fanar, despencar. A carnação de Gloria é mais fresca, era mais fresca, embora as duas mulheres tivessem mais ou menos a mesma idade, mas aquela juventude ainda tão orgulhosa de si mesma na véspera, hoje está enrijecida, quase congelada. Sabe-se lá por que é o pescoço que envelhece primeiro. Os amantes aspiram nele os mais suaves perfumes, ainda ambreados pelo suco visceral, mas aliviados pela atração dos olhos, da luz. Os lactentes nele se aninham, preferindo aquelas ondulações arejadas à tepidez sibilina dos seios e dos ventres. A cabeça lhe impõe seu peso, vertical aberração empoleirada em equilíbrio sobrenatural no cimo de um talo que se obstina em desafiar o peso e a flexibilidade horizontal dos quadrúpedes. Não se pode imaginar o quanto é fatigante manter-se de pé, firme, com amantes, bebês, e uma cabeça que deve pensar em tudo! Acumulação agradável por vezes, talvez gloriosa, mas cansativa, muito cansativa. O pescoço se ressente disso, ele afirma, acusa. O pescoço é o órgão mais sorrateiro e mais monstruosamente feminino. Em oposição ao grande artelho que, nos dois sexos, acumula os sofrimentos do corpo que pesa e trai as misérias do caráter, o pescoço - só nas mulheres acrescenta aos desgastes masculinos os indícios de um espírito covarde, assim como os de uma vida sem saída. E acaba por revelar essa tendência perpétua a desabar, a que chamamos estupidez - onipotência da inércia e da negligência. Impossível de maquiar, seria preciso fazer liftings, cortar, recosturar. Ou simplesmente arrancar, $\operatorname{cortar}^{10}$ (KRISTEVA, 1996, p. 204).

\footnotetext{
${ }^{10}$ La lame comprime la chair rigide du cou. La peau du cou vieillit la première chez une femme; tous les matins Pauline pince cette pomme cuite, s'agace plus ou moins tendrement de la voir brunir, faner, s'affaisser. La carnation de Gloria est plus fraîche, était plus fraîche, bien que les deux femmes aient eu à peu près le même âge, mais cette jeunesse encore si fière d'elle-même, la veille, est aujurd'hui raidie, quasi congelée. Allez savoir pourquoi c'est le cou qui prend de l'âge le premier. Les amants y flairent les parfums les plus suaves, encore ambrés du suc viscéral, mais allégés par l'attraction des yeux, du jour. Les nourrisons s'y nichent, préférant ces vallonnements aéres à la tiédeur sibylline des seins et des ventres. La tête lui impose son poids, verticale aberration juchée en équilibre surnaturel au sommet d'ue tige qui s'obstine à défier la pesanteur ainsi que la souplesse horizontale des quadrupèdes. On ne sait pas combien il est fatiguant de tenir debout avec amants, bébés, et une tête qui doit penser à tout! Cumul agréable parfois, glorieux si l'on veut, mais fatigant, très fatigant. Le cou s'en ressent, il assure, accuse. Le cou est l'organe le plus sournoisement, le plus monstrueusement féminin. À opposé du gros orteil qui, dans les deux sexes, accumule les souffrances du corps pesant et trahit les misères du caractère, le cou - chez les femmes seulement - ajoute aux usures masculines les indices d'un esprit lâche ainsi que ceux d'une vie sans issue. Et finit par révéler cette tendance perpétuelle à s'effondrer qu'on appelle stupidité - toute-puissante de l'inertie et du laisser-aller. Impossible à maquiller, il faudrait lifter, couper, recoudre. Ou simplement enlever, trancher (KRISTEVA. Possessions, Paris: Fayard, 1996, p. 243-244).
} 
Um dos aspectos do perecível que nos interessa em função de seu caráter universal diz respeito à maternidade - assunto central de qualquer estudo sobre o afeto, de teor filosófico desde Platão. Em $A$ revolução da linguagem poética, Kristeva observa numa carta de Mallarmé o sentimento de inveja do poeta que é compartilhado com um amigo diante da impossibilidade de gerar bebês: "nós só somos pais de nossas produções imaginárias" (1974, p. 449). A inveja acompanha a condição feminina, além de delinear o espaço sexual e o ritmo do que pode ser pensado, principalmente em filosofia. Vejamos as metáforas e os verbos nietzschianos que transformam o gelo em fogo de gestação de ideias, que são - é preciso lembrar às vezes - algo diferente de bebês:

não somos aparelhos de objetivar e registrar, de entranhas congeladas - temos de continuamente parir nossos pensamentos em meio a nossa dor, dando-lhes maternalmente todo o sangue, coração, fogo, prazer, paixão, tormento, consciência, destino e fatalidade que há em nós. Viver - isto significa, para nós, transformar continuamente em luz e fala tudo o que somos, e também tudo o que nos atinge; não podemos agir de outro modo (NIETZSCHE, 2007, §3, p. 12, grifos nossos).

Para além da inveja, Nietzsche reconhece, ainda que obliquamente, certa beleza grácil no feminino ao aproximar as mulheres das vacas - "gatas, eis o que são as mulheres ou pássaros, ou, melhor ainda, vacas" (Assim falou Zaratustra, "Do amigo", p. 85) - pavimentando assim o caminho desconstrutivo que atualmente se distribui em escolhas e estilos nos textos de Kristeva, que são carregados de sua própria condição estrangeira, que é também a nossa na afirmação da autora de que somos todos estrangeiros para nós mesmos ${ }^{11}$. É perifericamente, em correspondência com a amiga Catherine Clément, que as duas entram em contato com o que Nietzsche chamaria, com sabedoria de "existência e texto", do profundamente superficial da condição feminina. Clément escreve:

A vaca é, portanto, maternal e envolvente, admitamos. Os hindus tiram daí suas consequências: tudo aquilo que sai da vaca é não apenas sagrado, mas útil. Bebese o leite, faz-se a manteiga para a vida quotidiana, a mesma com a qual se vai aspergir o cadáver durante a cremação; come-se a nata que sobra, utiliza-se a urina como anti-séptico para limpar os assoalhos (CLÉMENT, 2001, p. 40).

O profundamente superficial retorna com duas pinturas de Georgia O'Keeffe, fotocopiadas por Kristeva,

\footnotetext{
${ }^{11}$ Referimo-nos à obra Estrangeiros para nós mesmos, mas o tema atravessa grande parte da produção de Kristeva.
}

e que participam do livro gerado pelas correspondências (eletrônicas) entre as intelectuais. A primeira delas chama-se "Série I, número 1", segundo Kristeva: "(um título que não quer dizer nada, mas a cor torturante desse botão obsceno faz vibrar o olhar e a carne)" (KRISTEVA, 2001, p. 52). A segunda tela chama-se "Crânio de vaca com rosas de algodão". No centro do quadro está o crânio de uma vaca, alvo, poroso, frágil, e duas rosas - o retorno do estilo imagético da pintora. As rosas e o crânio são quase da mesma tonalidade de branco. O material das rosas mistura-se à estrutura oca do crânio. Tanto o algodão das rosas quanto algumas rachaduras no crânio do animal, que se deixa ver nos tons amarelados, compõem uma atmosfera visual de dominação da cor branca, passando a ideia de vazio, semelhante àquela descrita por Kristeva em outro quadro da mesma pintora, qual seja, de um nada dentro da forma (como tocar os elementos semiotizáveis). Kristeva já havia escrito sobre O'Keeffe em Possessões (polar). Nesse romance policial, a autora cria um personagem com deficiência auditiva, cuja mãe é assassinada (Gloria Harrison) e ao mesmo tempo joga em cena um narrador que defende a ideia derridiana de (timpanização), a de que no horror não se vê - no horror se escuta. Todavia, ecoa no texto a seguinte questão: como "vive" o filho de Gloria Harrison diante desse imperativo ético/ estético que acompanha o movimento de desconstrução desde Nietzsche? Observamos que a referência às flores O'keeffianas reaparecem, a fim de chamar a atenção para a fragilidade (o perecível clariciano) ao lado da retomada de modalidades linguísticas (semiótico, simbólico) e outros conceitos que se adicionam à Revolução poética (de 1974), através da vida-e-obra de Colette. Escritora do gosto de Kristeva, Colette antecipa O'Keeffe ao descrever detalhes de flores, em complexo trabalho de descrição de cores e sabores, expandindo-se em minúcias de um açucaramento repleto de ternura comestível, que são retomadas pela teórica com o objetivo de oferecer respostas tanto ao impasse ético que está em Possessões quanto o desafio exposto em Sentido e contra-senso da revolta, no qual a sociedade, saturada de imagens, visibilidades mudas, sofre os impedimentos de um possível despertar (de ordem proustiana, semelhante ao penoso trabalho da tentativa da recriação do gosto da madeleine), de retomada e reinterpretação de alguns elementos semiotizáveis via linguagem. O jogo sinestésico, no entanto, realça o sabor como elemento-chave para desfazer as distinções radicais entre o pensar e o sentir - ou a ele se associa para enaltecer essa contaminação dos sentidos proposta por Kristeva (que acompanha suas pesquisas em Poderes do horror). Uma segunda vida-obra amplia os questionamentos sobre o pensar e sentir que tocam o aparelho fonador, constituindo, ao lado de Totem e tabu, uma conquista ética do pensar e sentir em seus limites e contaminações. 
Sem reconstruir a interpretação de Arendt sobre a relação tensa entre o particular e o universal presente na Crítica do juizo, simplificamos esse ponto complexo através da produção de abalo da estrutura antitética pensar/sentir para reconhecer um conteúdo de experiência vivida, na breve reconstrução que a própria Kristeva realiza da leitura kantiana de Arendt ( $A$ vida do espírito), enfatizando imagens gustativas. O nosso objetivo é o de sublinhar o realce metafórico que ela concede ao gosto. O gosto é um dos elementos semiotizáveis: "O que conta é esse apetite de pensamento que não cessa, em Arendt, de procurar os fundamentos do elo entre particular e geral, entre indivíduo e pluralidade, para justificar uma condição humana vivivel, tão livre quanto justa" (KRISTEVA, 2002, p. 205).

Nesse contexto, o tema da maternidade, em Hannah Arendt, se desenha através do cuidado sobre a questão da justiça, levando-a a percorrê-la entre a experiência vivida e a norma. Seria excessivo para os limites deste ensaio incluir outra vida-obra. No entanto, é na direção da retomada da produção de Melanie Klein e da exploração que desestrutura o primado do olhar (lacaniano), inserindo e reinterpretando o peso de afetos sobre a linguagem (inveja, gratidão, ternura, por exemplo), sua relação arcaica com o "gosto", com mamãe, com o mais íntimo, na acepção de Kristeva em A revolta íntima, seria por esse caminho que o universal deveria ser reavaliado, não como estrutura, mas como vida. A urgência dessa superfície profunda já anunciada, nietzschianamente muito antes da trilogia do gênio feminino, escreveu Clarice Lispector em Água viva:

Domingo é dia de ecos - quentes, secos, e em toda parte zumbidos de abelhas e vespas, gritos de pássaros e o longínquo das marteladas compassadas - de onde vêm os ecos de domingo? Eu que detesto domingo por ser oco. [...] Fico dormitando no calor estivo do domingo que tem moscas voando em torno do açucareiro (LISPECTOR, 1973, p. 18, grifos nossos).

\section{Referências}

ARTAUD, Antonin. Ouvres complètes. T. I, 1. Paris: Gallimard, 1984.

CIXOUS, Hélène. Three steps on the ladder of writing. New York: Columbia University Press, 1993.

DERRIDA, Jacques. A escritura e a diferença. Trad. Maria Beatriz Marques Nizza da Silva. 3. ed. São Paulo: Perspectiva, 2002.

DERRIDA, Jacques; BENNINGTON, Geoffrey. Circonfissão. Rio de Janeiro: Jorge Zahar Editor, 1996.

DERRIDA, Jacques. Gramatologia. 2. ed. Trad. Miriam Chnaiderman, Renato Janine Ribeiro. São Paulo: Perspectiva, 1999.
DERRIDA, Jacques. Khôra. Trad. Nícia Adan Bonatti. Campinas: Papirus, 1995.

DERRIDA, Jacques. La carte postale: de Socrate à Freud et au-delà. Paris: Flammarion, 1980.

DERRIDA, Jacques. Otobiographies. L'enseignement de Nietzsche et la politique du nom propre. Paris: Galilée, s/d.

DERRIDA, Jacques. Timpanizar a filosofia. Margens da filosofia. Campinas: Papirus, 1991.

FREUD, Sigmund. Totem e tabu. Trad. Órizon Carneiro Muniz. Rio de Janeiro: Imago, 1999.

GREEN, André. Le discours vivant: la conception psychanalytique de l'affect. France: PUF, 2004.

KRISTEVA, Julia. As novas doenças da alma. Rio de Janeiro: Rocco, 2002.

KRISTEVA, Julia. Étrangers à nous-mêmes. Paris: Fayard, 1991.

KRISTEVA, Julia. La révolte intime: pouvoirs et limites da psychanalyse II. Paris: Fayard, 1997.

KRISTEVA, Julia. La révolution du langage poétique. L'avantgarde à la fin du XIXe siècle. Lautréamont et Mallarmé. Paris: Seuil, 1974.

KRISTEVA, Julia. Le génie féminin: la vie, la folie, les mots. (Tome I) Hannah Arendt. Paris: Fayard, 1999.

KRISTEVA, Julia. Le génie féminin: la vie, la folie, les mots. (Tome II), Mélanie Klein. Paris: Fayard, 2000.

KRISTEVA, Julia. Le génie féminin: la vie, la folie, les mots. (Tome III), Colette. Paris: Fayard, 2002.

KRISTEVA, Julia. Le vieil homme et les loups. Paris: Fayard, 1991.

KRISTEVA, Julia; CLÉMENT, Catherine. O feminino $e o$ sagrado. Trad. Rachel Gutiérrez. Rio de Janeiro: Rocco, 2001.

KRISTEVA, Julia. O gênio feminino: a vida a loucura e as palavras: Hannah Arendt. Trad. Eduardo Francisco Alves. Rio de Janeiro: Rocco, 2002.

KRISTEVA, Julia. Possessions. Paris: Fayard, 1996.

KRISTEVA, Julia. Possessões. Trad. Maria Helena Franco Martins. Rio de Janeiro: Rocco, 2003.

KRISTEVA, Julia. Pouvoirs de l'horreur. Essais sur l'abjection. Paris: Seuil, 1980.

LISPECTOR, Clarice. A hora da estrela. Rio de Janeiro: Rocco, 1999.

LISPECTOR, Clarice. Água viva. São Paulo: Círculo do Livro, 1973.

LISPECTOR, Clarice. O lustre. Rio de Janeiro: Rocco, 1999.

LISPECTOR, Clarice. Perto do coração selvagem. Rio de Janeiro: Rocco, 1998.

MÈREDIEU, Florence. C'était Antonin Artaud. Paris: Fayard, 2006.

NIETZSCHE, Friedrich. A gaia ciência. Trad. Paulo César de Souza. São Paulo: Companhia das Letras, 2007.

NIETZSCHE, Friedrich. Além do bem e do mal. Trad. Paulo César de Souza. São Paulo: Companhia das Letras, 1992. 
NIETZSCHE, Friedrich. Assim falava Zaratustra. Trad. Mário Ferreira dos Santos. Porto Alegre: Vozes, 2008.

NIETZSCHE, Friedrich. Ecce Homo: como alguém se torna o que é. Trad. Paulo César de Souza. São Paulo: Companhia das Letras, 1995.

NIETZSCHE, Friedrich. Genealogia da moral. Trad. Paulo César de Souza. São Paulo: Companhia das Letras, 1998.

NIETZSCHE, Friedrich. Humano, demasiado humano. Trad. Paulo César de Souza. São Paulo: Companhia das Letras, 2000.

ROUDINESCO, Elisabeth; DERRIDA, Jacques. De que Amanhã: diálogo/Jacques Derrida; Elisabeth Roudinesco. Trad. André Telles. Rio de Janeiro: Jorge Zahar, 2004.
SOUZA, Ricardo Timm. Derrida e a razão diferencial. In: SOUZA, Ricardo Timm. Razões plurais: itinerários da racionalidade no século XX: Adorno, Bergson, Derrida, Lévinas, Rosenzweig. Porto Alegre: EDIPUCRS, 2004.

THÉVENIN, Paule. Antonin Artaud, ce désespéré qui vous parle. Paris: Seuil, 1993.

Recebido: $12 / 04 / 2018$

Aprovado: 20/04/2018

Contato:

Luciana Abreu Jardim <lucianajardim.1@hotmail.com> 